\title{
IMPACT OF DIGITAL FACTORY TOOLS ON DESIGNING OF WAREHOUSES
}

\author{
Monika Bučková* \\ University of Zilina, Faculty of Mechanical Engineering, Slovakia \\ Martin Krajčovič \\ University of Zilina, Faculty of Mechanical Engineering, Slovakia \\ Boris Jerman, \\ University of Ljubljana, Faculty of Mechanical Engineering, Slovenia
}

In this article the basic information for cost reduction in warehouse facilities by use of new technologies is presented. The core of article constitutes of the description of new technologies and their impact on design warehouses. The article discusses the influence of new technology on the way the data is collected, on the storage of goods, their processing and on the sequences of delivery of goods to customers in the requested format and quality.

Key words: Warehouses, Logistics, 3D designing, Static analysis, Simulation

\section{INTRODUCTION}

One of the most important parts of company logistics system is storage which somehow intersects space and time. It's an activity where the physical and other parameters of the stored material should not change. From an economic point of view the stored material do not gain greater utility value; on the contrary, the storing gives rise of costs, which further affect the profitability of products. Therefore, the logical action of companies is to minimize their stocks and thus minimize the storage costs. Storage and its proper functioning has a significant impact on ensuring a higher level of customer service and on protection of utility value of goods [05]. The possibility of usage of software for 3D warehouse designing, for fast static capacity calculations and for computer simulations of warehouse operations during early stages of the designing process (development of technologies, design of warehouses and their logistics) present an obvious advantage. It allows systematic control of the design process, by which the balance between goals and resources of the company can be achieved. Through the numerical calculations of factors which affect storage process, the so called "bottle necks" and other problematic areas of the warehousing process can be identify. Because of the increasing demands for the reduction of the time between the issuance of individual parts or semi-products from the storage, the emphasis on quality stor- age design and preparation of storage processes is increasing. Such a preparation can detect and eliminate problems in storage processes in the planning phase before putting the semiproduct into the real-world production or before the shipment of goods to customers. Between main questions that for warehouse planning and designing can be included for example [01]:

- Specify way how to evaluate the effectiveness of storage management.

- Specify the methods of picking or of modifications of goods according to the order.

- Capacity planning in the warehouse.

- Editing and evaluation of material flow in the warehouse.

- Analysis of the influence of automated systems on warehouse management.

- Labor needs, etc.

Methods of digital factory as 3D modeling, automated static capacity calculations, computer simulation and automated data collection can provide us answers to these questions. These methods belong to main current trends in designing of warehouses. Between other trends we can for example include [01]:

- Globalization (integrated logistics, creating global markets, global competition and production, worldwide sales and purchase).

- Pressure to reduce costs to remain competitive in global markets. 
- Requirements of customers for personalized products and services.

- New information and communication systems and technologies.

- Legislative requirements (for example Waste act, Green logistic concept).

- Increasing demand for specialty workers.

\section{DESIGNING OF WAREHOUSE}

Designing of warehouse is complicated, multilevel system, which is continually influenced by various factors. Project of warehouse designing requires implementation of several basic steps:

Specification of warehousing program

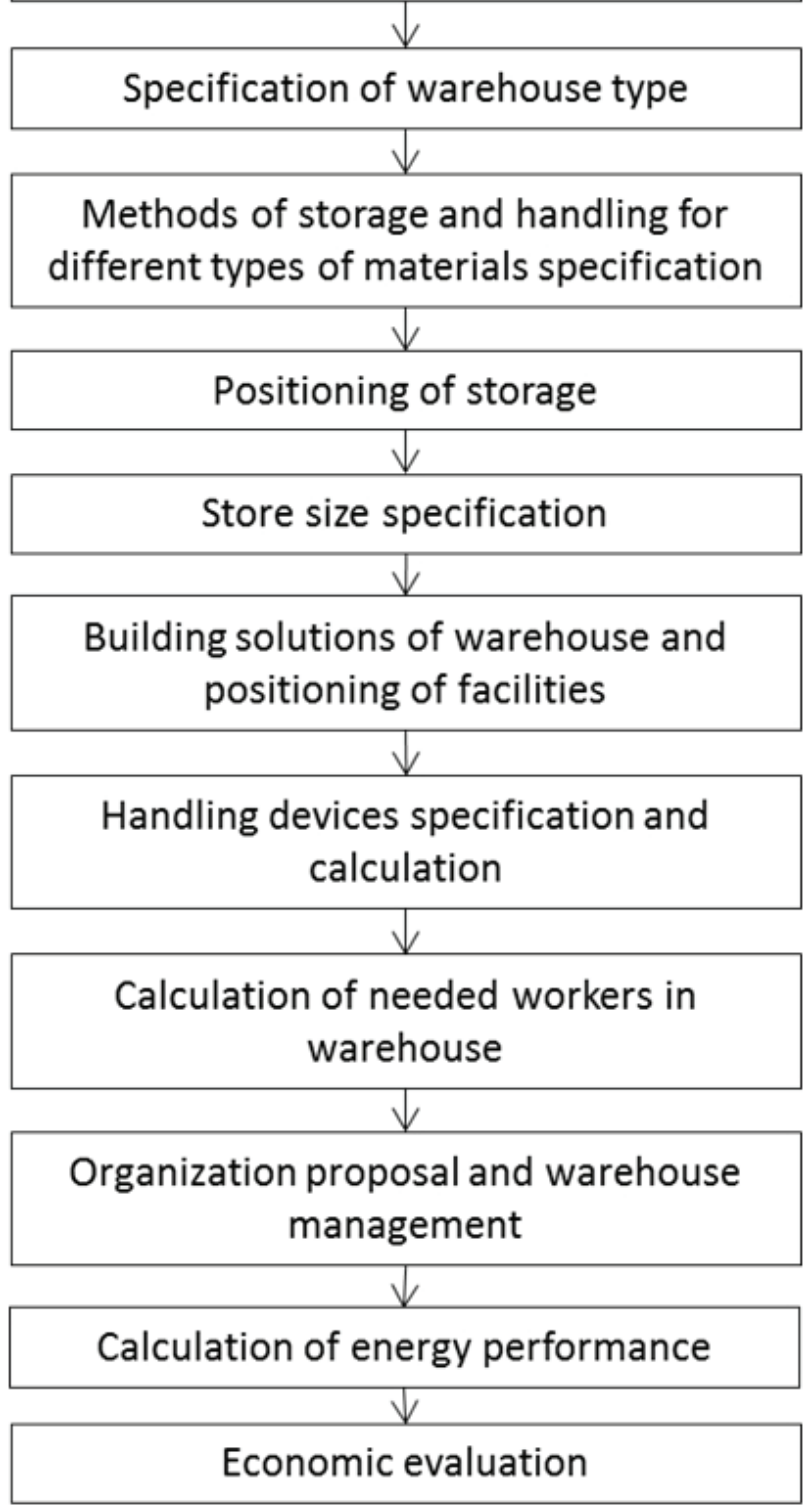

Figure 1: Steps of warehouse designing
We can divide all basic steps into three main phases:

1) Phase - Technical solutions of warehouse

2) Phase - Layout of warehouse

3) Phase - Organizational solutions of warehouse

This complicated, creative activity requires highly qualified specialists. Members of designing team are selected according to phase of designing. Therefore designed model of storage must be simple, information must be clear and communication between team members must be prompt.

\section{WAREHOUSE DESIGNING USING DIGITAL FACTORY}

Modern warehouses are working in dynamic environment of global supply chains.Companies must be able to compete in dynamic markets. Therefore quick design of warehouse and logistics processes is essential. As it is important in companies to plan deployment of assembly or production workplaces, it is important to plan storage and logistic processes. In recent years companies begin to use digital factory concept to accelerate designing process and to eliminate risk of wrong design. Digital factory represents the most progressive approach to complex, integrated design of products, manufacturing processes and manufacturing systems. Concept of digital factory is based on three elements [09]:

- Digital product with its static a dynamic aspects.

- Digital design of manufacturing process.

- Digital manufacturing with usage of planning data for increasing company processes.

Digital factory modules designed for warehousing and logistics offer all necessary features for design and verification of all aspects of warehousing process. Processes of storage and warehouse logistics can be visualized with 2D and 3D animation and improved by connecting individual software solutions for 3D design, static parameters calculation and computer simulation. Digitizing, modeling, simulation and emulation are used to understanding of comprehensive manufacturing processes and creation of new knowledge, which is used for optimization of real production systems [06]. 
Modern computer equipmentcomplemented with warehouse designing software allows transition from standard technology design (for example mechanical drawings in $2 \mathrm{D}$ view) to complete $3 \mathrm{D}$ view on storage model and to dynamic verification of processes using computer simulation.
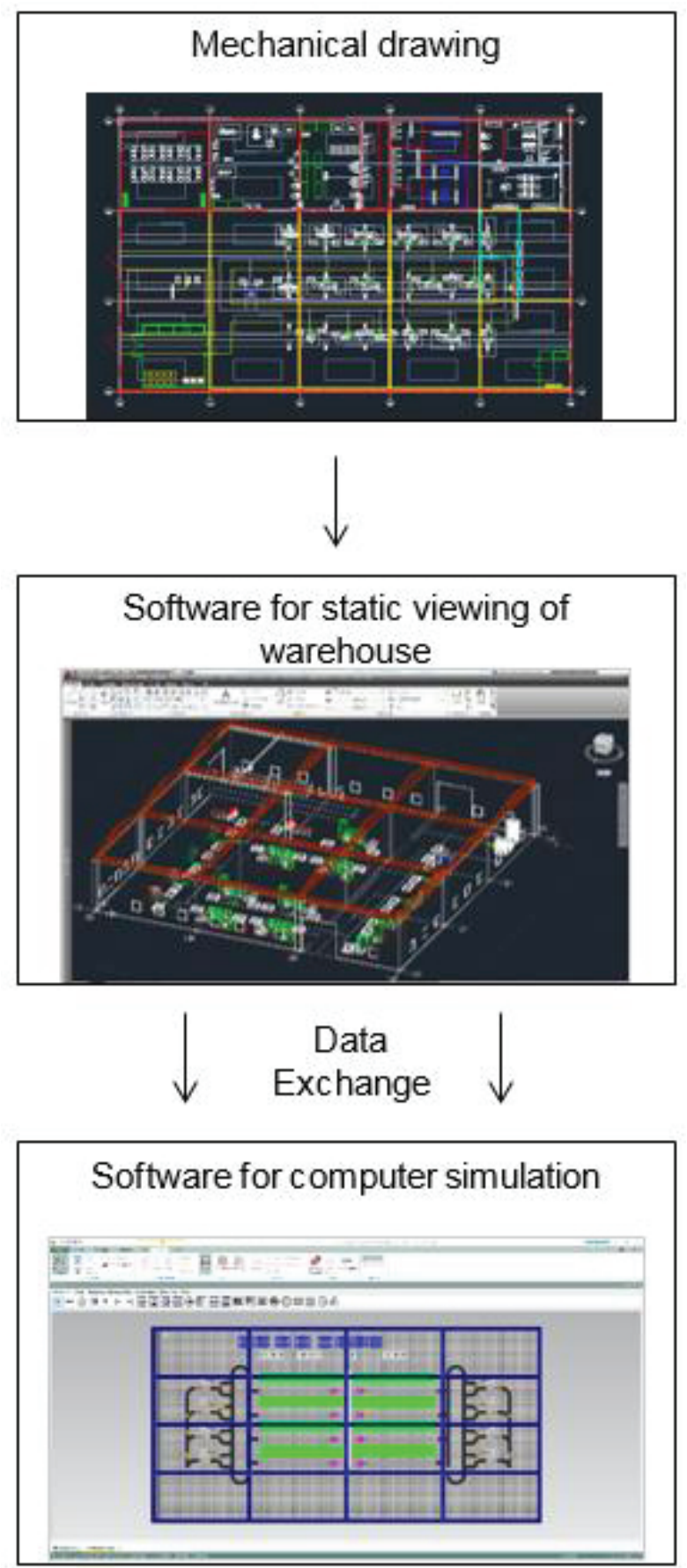

Figure 2: Software connection between Factory $C A D$

/ Flow and Tecnomatix Plant Simulation 12.1

Processes of 3D storage designing are currently changing. They are characterized by aspects such as rising complexity, shortening intermediate times, larger development teams, same development goals, globally operating com- panies, direct production to international markets, working with electronic documentation etc. We can include between main requirements for realization of virtual development environment:

- Optimized business processes.

- The availability of electronic data about products and processes for all team members.

- Electronic documentation.

- Communication interface to outside world.

- Easy to use of all tools at workplace, for example: through tablet, phone, etc.

The impact of new trends and continued development of technologies causes, that tools and methods of digital factory can be currently included into all steps of warehouse designing. Digital factory tools is used as sectional element and we can use it as communication tool to exchange data in various design phases.

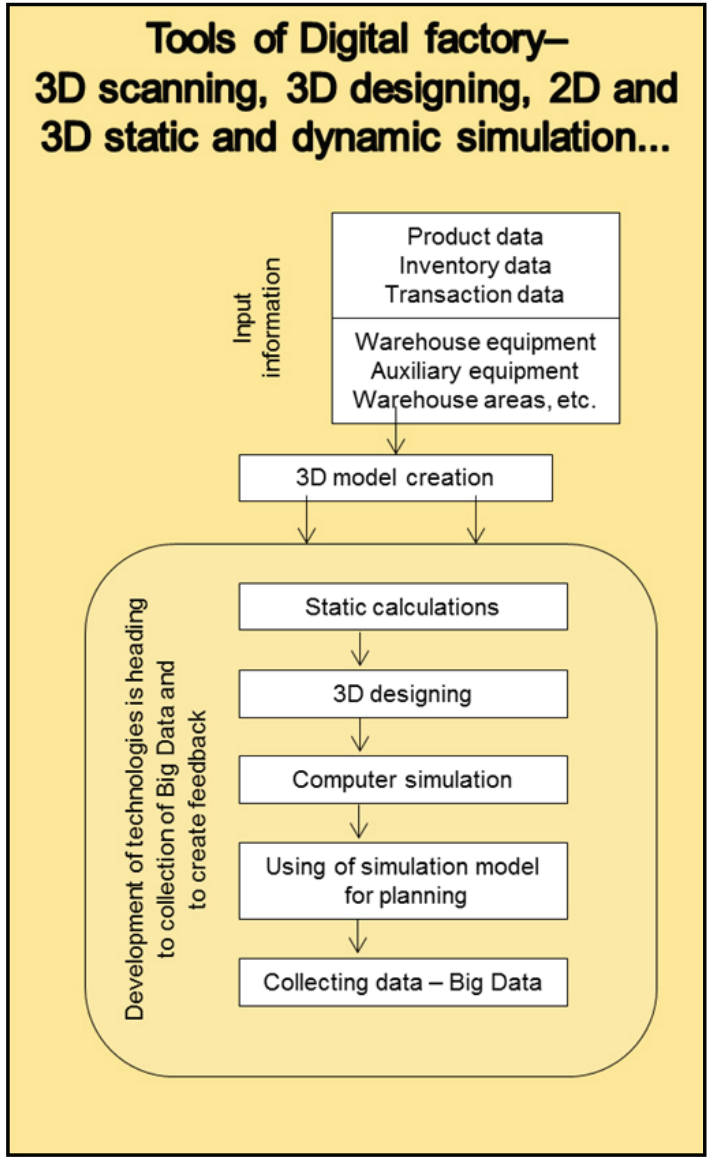

Figure 3: Using digital factory tools for designing warehouse scheme

Development of above mentioned requirements causes that 3D designing, static calculations, computer simulation and system for automated data collection are gradually included in initial steps of warehouse and logistics designing. 
Implementation of these tools moves towards to collection constantly greater number of data. Thereforeconnectivitybetweensystemsshould be the first condition of successful usage of systems.

\section{INPUT INFORMATION FOR WAREHOUSE MODELS CREATION}

Necessary data to establish program of warehousing are based on production plan, yearly quantity of production and norms of material consumption per product. From these data, will be determined yearly need for different types of materials. All collected data that software can get are important for creation of individual logistics elements statistics. Calculated statistics are basis for optimization or improvement. Therefore, at the beginning of designing and improving, it is important to select goals such as reducing costs, improving inventory levels, service levels, improve ROI values etc.

The most important step is enabling software to collect data, to sort data, to process them and then to send them to team members online. Members can make better decision while designing processes with collected information.

\section{D MODELLING}

During the first phase of designing of warehouse and its logistics is appropriate to start with 3D digitizing because it facilitates and accelerates another analyses of input data. Digitalization opens the door to great opportunities. The digital future will combine the products with the software solution, which is already happening [10]. For creating 3D models of warehouse and logistics elements can be used manual collection of information, created 3D libraries or 3D laser scanners. Created 3D models are basis for creating mechanical drawings, for design of most suitable warehouse area arrangement, for optimization of material flows and for final visualization of the designed solution.

The combination of software applications with hardware resources like 3D projectors, 3D cameras, 3D scanners, allows interpretation of future warehouse real picture in virtual reality [03]. Information obtained in the first step of warehouse designing is used to create models of warehouse hall, manipulated objects and logistics. Created objects and their individual elements can be flexibly animate in software. New possibilities of software allow adding and removing these ani- mation points, visualize them and hiding them. It is possible to place object in warehouse layout with accuracy of millimetres, and to rotate objects by using these added animation points.

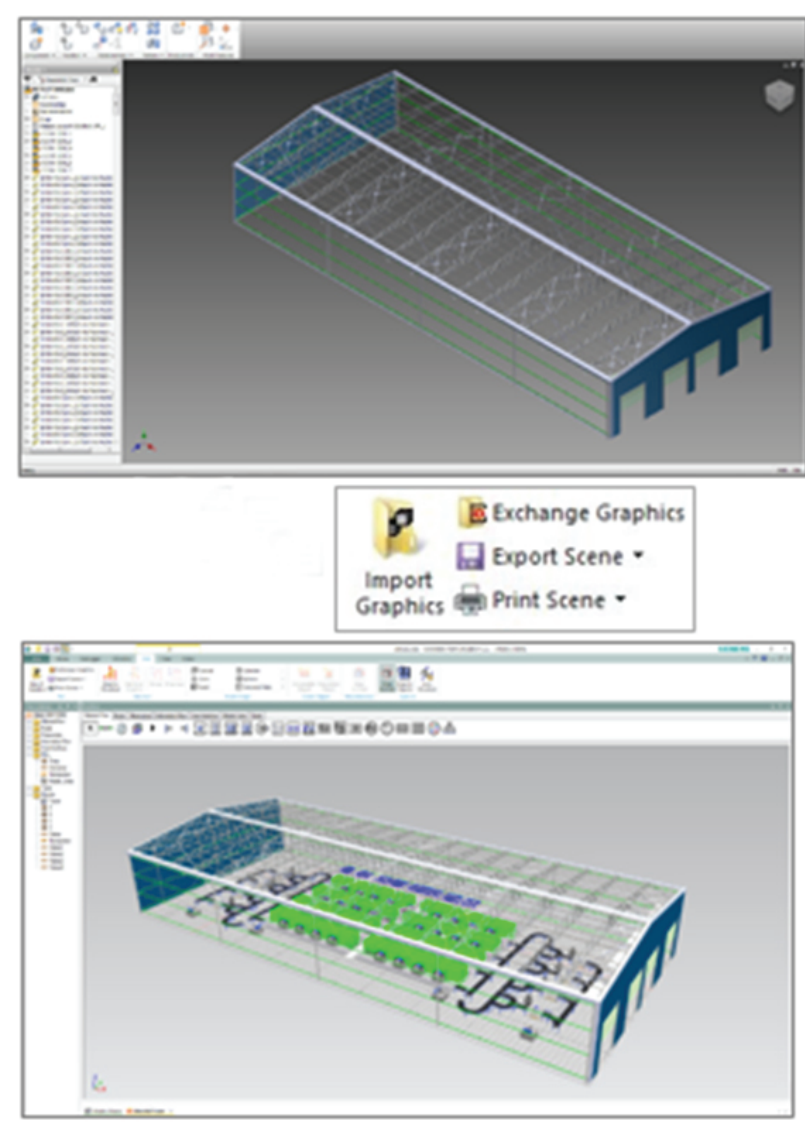

Figure 4: Object created in Inventor Professional, stored in the form .JT then uploaded to Tecnomatix Plant Simulation

Enrolment of graphical inheritance depends on created graphics. It is always necessary to duplicate entire graphic object. This duplication of facilities is particularly challenging for the graphics card of computer. Long processing graphic data can cause problems with model rendering. Therefore it was developed option to create our own 3D libraries. It is possible to create own special folder where own specific models can be saved and thereby reduce duplication time of model it's processing. In this step the process of define 3D models and interconnectivity between various software is important, because it facilitates the work of team members.

\section{D LAYOUT DESIGN AND STATIC CALCULATION DURING WAREHOUSES DESIGNING}

$3 \mathrm{D}$ designing is applicable in design of warehouse building and in verification conflict situations between static and dynamic elements 
is to use single database of $3 D$ models for all software tools and ability to use 3D models that are constantly updated. Perfect example is connection between software for 3D designing, static capacity calculation and computer simulation, where same database can remove duplication of data collection and data evaluation.
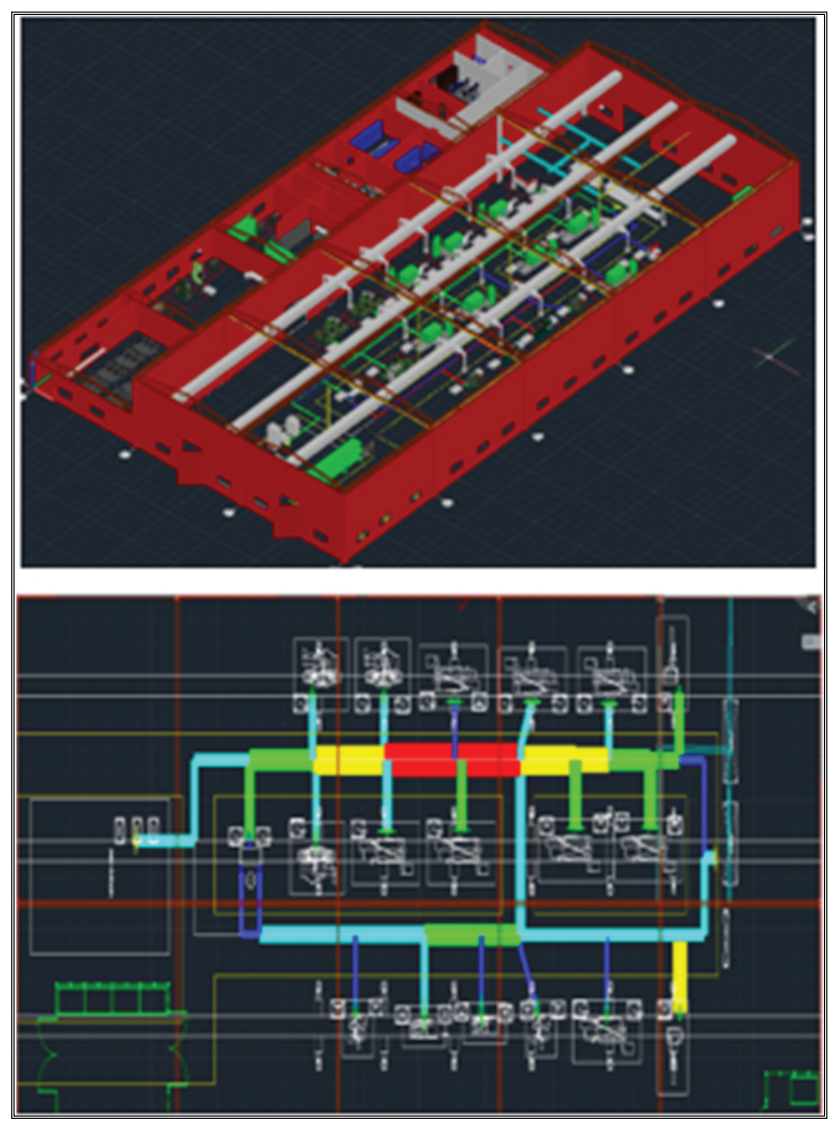

Figure 5: Viewing material flow in the software for $3 D$ designing and static analyses Factory CAD / Flow

Connected software modules for 3D designing, for static capacity calculation and optimization of material flow objects makes it possible to improve layout of warehouse and calculate logistic capacity in one step. You can analyses using such as connection for example:

- Transport distances.

- Frequency of transport included with transport costs.

- Total length of material flow.

- Total number of rides.

- Total time of transport and handling.

- Quantity of transport material.

- Unavailable time of transport equipment.

- Total capacity of transport equipment.

- Needed warehouse space, etc.
Software for analysing material flow offer possibility of creating analyses, reports, graphs that are basis for improving warehouse logistic solutions. They are primarily used in process of detailed store design. The disadvantage of software designed for 3D design and static calculation can be small range of analyses implemented into software, impossibility or small possibility to create own specific analyses for individual companies. Software for static analyses and 3D viewing of warehouses also do not involve sequence of processes in analysis. Therefore warehouse design should continue with computer simulation after 3D design and static analysis.

\section{COMPUTER SIMULATION IN WAREHOUSE DESIGNING}

Computer simulation allows effectively emulate and predict behaviour of selected dynamic process considering to their abilities and has many benefits. It helps managers at all levels of company to make responsible decision. It is based on capturing of real state or expected state of production system, its essential processes inside system and connections to external systems which may affect the entire production system and transformation them as computer model to virtual world, where we can make experimentations with virtual system. Simulation is one of the best tools for experimenting with proposals to improve material input processes, deployment of goods in warehouse, goods despatch or delivery processing etc. Every change is made in virtual enterprise and therefore we can decide which alternative is suitable for us before we implement this change in real system [02]. Pre-designed layout and concept of processes serves as basis for creation of conceptual simulation models. After conceptual simulation models are approved they will accelerate creation of detailed simulation models. We can described several steps to use simulation model in detailed warehouse design:

1) Creating of conceptual model - Conceptual design simulations should be easy to use and facilitate effective communications. During this design phase, many options remain open including site and warehouse layout, delivery schedules and operating hours. Unfortunately, historical data often is not avail- 
able, let alone detailed equipment specifications. However, the extensive capabilities of simulation software support conceptual simulations that facilitate quick ware house design, process flow animation and the visualization of key performance indicators. [11]

b) Detailed warehouse design - This step determinates many warehouse specification: capacity of warehouse and handling units, turnover of product range, size of production and transport batch, capacity of operators.

c) Creation of detailed simulation model - Creation of a model created on the basis of approved and verified data from detailed design.

d) Evaluation of simulation results - set, selection and evaluation indicators, which the company wants to monitor. This phase also shows influence of random events on warehouse and helps to select so called "bottle necks".

e) Planning and optimization of operations - We can use found "bottle necks" to optimize layout and processes in warehouse. Optimization answers the question: What can ensure optimal outputs of a given model when changing values of inputs? As objective and universal criterion of optimality in warehouses, the total costs of warehouse are most often used [04].

f) Creation of final version of warehouse layout and final version of designed processes.

g) Selection of data collection method - estimate connection between simulation model and designed warehouse by clarifying question of how the simulation model will be used for daily/weekly planning, how data will be collected and how to process these data.

h) Redesign of existing processes - editing model and other proposals to experiment with it - At various intervals, every warehouse operation requires redesign. For example, redesign usually becomes necessary when new customers have to be served or technological innovations are introduced. Simulation is extremely valuable in these instances. Accurate data is readily available for existing operations. Simulation is perfect tool to address even the most challenging redesign efforts. You can quickly and accurately build simulation models, as well as communicate alternative designs and results in clear reports and 3D animations [11].
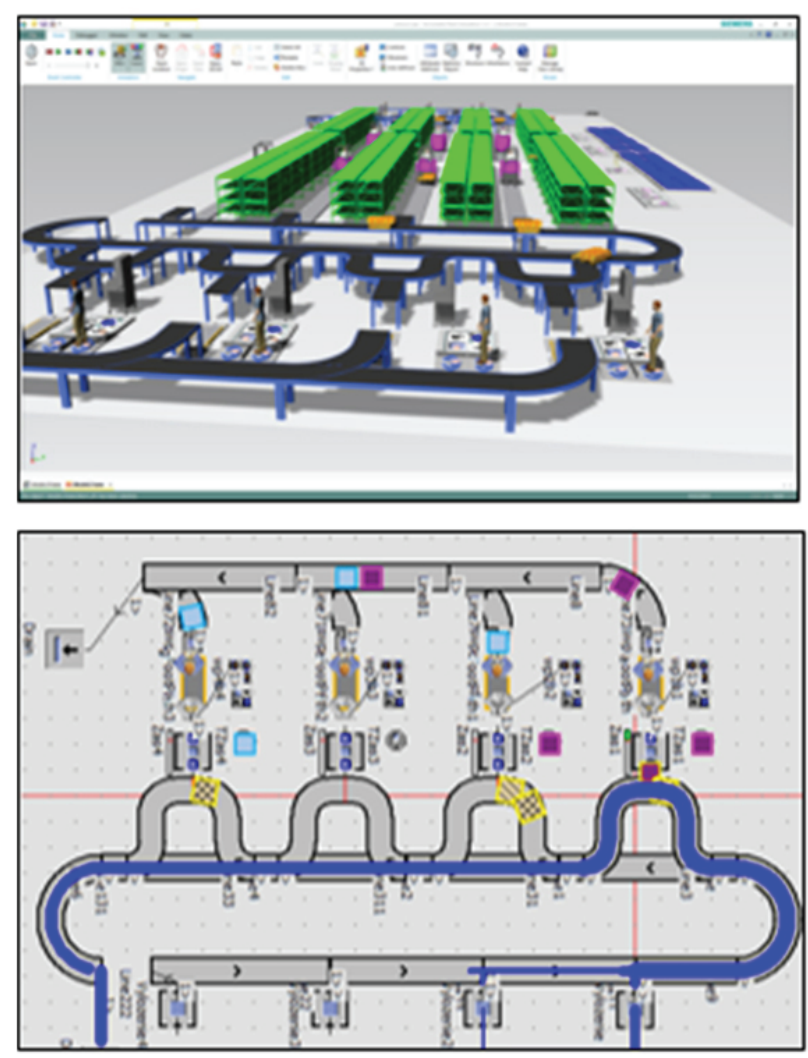

Figure 6: Visualization of material flow in software Plant Simulation

The most important connecting element between each step from 3D modelling to computer simulation is feedback. All software components effect on how the warehouse and logistics will be designed. Changes made in detailed simulation models should be able to transfer back to layout and to designing of processes. Therefore common database is needed.

\section{AUTOMATED DATA COLLECTION}

Feedbacks manage behaviour of complex systems. Therefore feedbacks are very important for modelling and simulation. One of the biggest mistakes in use of computer simulation in designing of warehouses is not to transfer simulation model from designing phase to phase of planning and management in daily functioning of store. Model must be prepared for using during designing phase and also for working in daily planning. If model has right construction we can implement into model data from forecasts as well as data from real "world" during daily work of warehouse.

Therefore it is necessary to have regard on technology of automated data collection and data acquisition while designing store and building simulation model. Recent software for automat- 
ed data collection and processing data allow:

- Securing wireless communications networks.

- Monitoring and supervision of logistic vehicles.

- Automatically control of logistic elements in system.

- Remote elements monitoring of logistic system.

- To gather data and information on operations for further processing.

- Process collected data and create reports and analyses like special OEE software for transport equipment.

- Planning logistic resources based on collected data.

- Generate and share analysis results to other software - for example: software for computer simulation.

This data can be used in simulation software to make periodic simulations of requirements for warehouse and to estimate capacity utilization in logistics. For example introduction of automated logistics brings out significant time savings when transferring material even guarantee delivery of material to the production line at the right time and quantity without potential human errors [08]. Enterprises need to have an integrated telecommunications network and information technology through which they can transmit the necessary information and dates within the organization too [07].

Using and automatization of data collection process, transmission for computer simulation, automatic periodic runs of simulation model and automatic generation of results can be used to create warehouse control mechanism. This mechanism is capable for early detection of massive requirements on storage capacities and to alert managers for intervention. Using such a simulation model managers can test multiple variations of corrective actions and select the most suitable solution in terms of capacity and economic indicators. Therefore the use of digital factory tools is advantageous. Usage of these tools do not end in warehouse designing. These tools can be used in planning of daily activities in warehouse with right setup of processes and appropriate combination of software solutions. Remote and real-time assessment of machine's performance requires an integration of many dif- ferent technologies including sensory devices, reasoning agents, wireless communication, virtual integration and interface platforms [05].

\section{CONCLUSION}

Submitted processing of new trends using and their impact on warehouse designing indicates greater need for digital factory tools using in designing and optimizing storage. Through right chosen indicators, it is necessary to create model that will be able to exchange data between the designers, warehouse and managers. Correctly selected sequence of steps and use of 3D design in early stages of warehouse designing should be also used to support management decisions. Managers should have software that can analyse several potential solutions and allows to select the only one with the best output parameters. Further research and development in area of designing stores with using digital factory tools speeds up process of company logistics planning and improves warehouse management. Digital factory will increase quality and accuracy of management decisions and decrease time to adopt to new situations with greater potential for costs savings.

\section{ACKNOWLEDGEMENT}

This paper is the part of research supported by project KEGA 004ŽU-4-2016.

\section{REFERENCES}

1) Dilský, S. (2014). Návrh systému interaktívneho logistického plánovania. Žilinská univerzita v Žiline - Strojnícka fakulta - Katedra priemyselného inžinierstva. Dizertačná práca 1 CD ROM.

2) Dilský, S. (2013). Simulation using digital factory software tool: Plant simulation. In AIE - Advanced industrial engineering: Monograph. (pp. 67-80). Bielsko-Biała. ISBN 97883-927531-6-2.

3) Furmann, R. (2011). 3D laser scanning: Support the implementation the digital factory. In Digital factory management methods and techniques in engineering production. (pp. 25-28). Bielsko-Biała: Wydawnictwo Akademii techniczno-humanistycznej.

4) Furtáková, S., Gregor, M., \& Hnát, J. (2014). Simulation Metamodelling of Chosen Production System. In: FAIM: Proceedings of the 24th International Conference on Flex- 
ible Automation \& Intelligent Manufacturing - Capturing Competitive Advantage via Advanced Manufacturing and Enterprise Transformation. Lancaster, USA: DEStech, Pennsylvania 17602.917-926.

5) Gregor, M., Haluška, M., Fusko, M., \& Grznár, P. (2015). Model of Intelligent Maintenance systems. In: 6th DAAAM International Symposium on Intelligent Manufacturing and Automation. 1097-1101. doi:10.2507/26th. daaam.proceedings.154

6) Gregor, M., Herčko, J., \& Grznár, P. (2015). The Factory of the Future Production System Research. In: ICAC: Proceedings of the 21st International conference on automation and computing, Glasgow, UK. Glasgow, UK.101105. doi:10.1109/IConAC.2015.7313998

7) Mičieta, B., Biňasová, V., \& Haluška, M. (2014). The approaches of advanced industrial engineering in next generation manufacturing systems. Communications: Scientific letters of the University of Žilina, 16(3A),
8) Mičieta, B., Herčko, J., Botka, M., \& Zrnić, N. (2016). Concept of intelligent logistic for automotive industry. Journal of Applied Engineering Science, 14(2), 233-238. doi:10.5937/ jaes14-10907

9) Palajová, S. (2012). Simulačné metamodelovanie výrobných systémov. (p. 149). Žilinská univerzita v Žiline - Strojnícka fakulta - Katedra priemyselného inžinierstva. Dizertačná práca.

10) Rakyta, M., Fusko, M., Herčko, J., Závodská, L., \& Zrnić, N. (2016). Proactive approach to smart maintenance and logistics as a auxiliary and service processes in a company. Journal of applied engineering science, 14(4), 433-442. doi:10.5937/jaes14-11664

11) Retrieved from http://www.cardsplmsolutions. $\mathrm{nl} /$ en/plm-software/tecnomatix/plant-simulation-warehousing -logistics-7 2016 Jun 20.

Paper sent to revision: 21.02.2017.

Paper ready for publication: 27.04.2017. 